\title{
Phase transformation and conductivity in nanocrystal PbS under pressure
}

\author{
Jiang, Jianzhong; Gerward, Leif; Secco, R.; Frost, D.; Olsen, J. S.; Truckenbrodt, J.
}

Published in:

Journal of Applied Physics

Link to article, DOI:

$10.1063 / 1.372235$

Publication date:

2000

Document Version

Publisher's PDF, also known as Version of record

Link back to DTU Orbit

Citation (APA):

Jiang, J., Gerward, L., Secco, R., Frost, D., Olsen, J. S., \& Truckenbrodt, J. (2000). Phase transformation and conductivity in nanocrystal PbS under pressure. Journal of Applied Physics, 87(5), 2658-2660.

https://doi.org/10.1063/1.372235

\section{General rights}

Copyright and moral rights for the publications made accessible in the public portal are retained by the authors and/or other copyright owners and it is a condition of accessing publications that users recognise and abide by the legal requirements associated with these rights.

- Users may download and print one copy of any publication from the public portal for the purpose of private study or research.

- You may not further distribute the material or use it for any profit-making activity or commercial gain

- You may freely distribute the URL identifying the publication in the public portal

If you believe that this document breaches copyright please contact us providing details, and we will remove access to the work immediately and investigate your claim 


\title{
Phase transformation and conductivity in nanocrystal PbS under pressure
}

\author{
J. Z. Jiang ${ }^{\text {a) }}$ and L. Gerward \\ Department of Physics, Building 307, Technical University of Denmark, DK-2800 Lyngby, Denmark \\ R. Secco and D. Frost \\ Bayerisches Geoinstitut, Universität Bayreuth, D-95440 Bayreuth, Germany \\ J. S. Olsen \\ Niels Bohr Institute, Oersted Laboratory, DK-2100 Copenhagen, Denmark \\ J. Truckenbrodt \\ HASYLAB am DESY, Notkestrasse 85, D-22603 Hamburg, Germany
}

(Received 27 July 1999; accepted for publication 12 October 1999)

\begin{abstract}
The grain-size effect on the phase transition induced by pressure in PbS was studied by in situ high-pressure electrical resistance and synchrotron radiation $\mathrm{x}$-ray powder diffraction measurements. The mean transition pressure of the B1-to-B16 phase transformation was found to be $6.3 \pm 1.3 \mathrm{GPa}$ in $8 \pm 1 \mathrm{~nm} \mathrm{PbS}$ while it is $3.1 \pm 0.7 \mathrm{GPa}$ for $10 \mu \mathrm{m} \mathrm{PbS}$. The resistivity of the B16 $\mathrm{PbS}$ phase decreases exponentially with pressure in both samples at ambient temperature. They follow $R \propto \exp (-C P)$, where $C=-0.64 \mathrm{GPa}^{-1}$ for $10 \mu \mathrm{m} \mathrm{PbS}$ and $C=-0.34 \mathrm{GPa}^{-1}$ for 8 $\pm 1 \mathrm{~nm} \mathrm{PbS}$. These results are discussed in terms of a decrease of energy band gap with increasing pressure. (C) 2000 American Institute of Physics. [S0021-8979(00)02102-2]
\end{abstract}

Nanocrystals, consisting of small crystallites with diameters 1-100 nm, often have novel physical and chemical properties, differing from those of the corresponding bulk materials. ${ }^{1}$ For example, nanometer-sized semiconductors exhibit particle size dependence of electronic and optical properties, making them potential candidates for applications involving tunability of these properties. ${ }^{2,3}$ Recently, Tolbert et al. ${ }^{4-6}$ studied structural phase transformations in $\mathrm{Si}, \mathrm{CdSe}$, and CdS nanocrystals, and found that the smaller the crystallite, the higher the transformation pressure. They explained the increase in transition pressure for the nanocrystals in terms of surface-energy differences between the phases involved. A similar explanation to the enhancement of transition pressure was also reported in nanocrystals of $\mathrm{ZnS}$ in Ref. 7 and of $\mathrm{ZnO}$ in Ref. 8 compared with corresponding bulk materials. However, Jiang et al. ${ }^{9}$ reported that for nanometer-sized $\gamma-\mathrm{Fe}_{2} \mathrm{O}_{3}$ particles the phase transition pressure (from $\gamma-\mathrm{Fe}_{2} \mathrm{O}_{3}$ to $\alpha-\mathrm{Fe}_{2} \mathrm{O}_{3}$ ) is lower than that for bulk material. They suggested that the larger volume change upon transition in the nanocrystals is the main factor in this case. A reduction of the transition pressure was also found in nanocrystals of $\mathrm{TiO}_{2}$ for the rutile-to- $\alpha-\mathrm{PbO}_{2}$ transition. ${ }^{10} \mathrm{It}$ seems that the grain-size effect on the transition pressure can be of either sign, depending on the system under investigation. However, the mechanisms governing the structural stability of nanocrystals are not well understood. More data for the grain-size effect on structural stability in various systems are desirable.

At ambient temperature, bulk $\mathrm{PbS}$ has a phase transformation at 2.2 GPa from a NaCl-type structure (B1) to a black phosphorus-type orthorhombic structure (B16). ${ }^{11}$ Qadri

a) Author to whom correspondence should be addressed; electronic mail: jiang@fysik.dtu.dk et al. ${ }^{12}$ have reported synchrotron radiation energydispersive high-pressure $\mathrm{x}$-ray powder diffraction measurements of $\mathrm{PbS}$ with three different grain sizes. They found that onset and completion pressures of the B1-to-B16 transition increase with decreasing grain size. However, due to small grain sizes and the fact that B16 is a distorted cubic B1 phase, the broad diffraction lines of B1 and B16 phases strongly overlap. Consequently, the determination of the transition pressure for the $\mathrm{B} 1$-to-B16 transformation in $\mathrm{PbS}$ using the $\mathrm{X}$-ray powder diffraction technique becomes questionable. In addition, the behavior of the mean transition pressure versus grain size in $\mathrm{PbS}$ is still unclear. Therefore, a reexamination of grain-size effect on the phase transition using different techniques in $\mathrm{PbS}$ is warranted. In this communication, we present in situ high-pressure conductivity and $\mathrm{x}$-ray powder diffraction investigations on the phase transition in bulk and nanostructured $\mathrm{PbS}$.

Two PbS samples with average grain sizes of approximately $10 \mu \mathrm{m}$ (hereafter called bulk) and $8 \pm 1 \mathrm{~nm}$ (hereafter called nanocrystals) were investigated. $\mathrm{PbS}$ powder $(10 \mu \mathrm{m})$ with a $99.9 \%$ purity was used as a starting material for the synthesis of nanometer-sized $\mathrm{PbS}$ samples using a Planetary ball mill (Fritsch Pulverisette 5), with tungsten carbide vials and balls. A single phase with a NaCl-type structure (B1) in the samples studied was confirmed by $\mathrm{x}$-ray powder diffraction. The average grain sizes of milled samples and the starting material were estimated by $\mathrm{x}$-ray powder diffraction and by scanning electron microscopy, respectively. High resolution transmission electron microscopy measurements revealed the presence of lattice fringes and confirmed the B1 structure in the samples. Tungsten contamination in the milled samples, originating from abrasion of the vial and balls, was found to be less than 0.5 at. \% from energydispersive x-ray analysis. High-pressure in situ electrical re- 


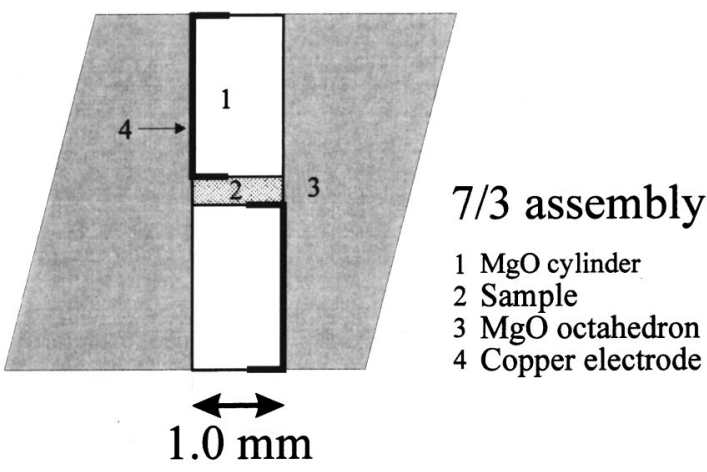

FIG. 1. Sample assembly for high-pressure in situ electrical resistance measurements at ambient temperature.

sistance measurements at ambient temperature were carried out at Bayerisches Geoinstitut in Bayreuth, Germany, in a 1200 ton multianvil apparatus using $7 \mathrm{~mm}$ edge length octahedral pressure cells (Fig. 1). Copper foils were used as electrodes to measure the dc resistance across a sample disk approximately $1 \mathrm{~mm}$ in diameter and $0.2 \mathrm{~mm}$ thick. Resistance measurements were made on increasing pressure using a previous determined pressure calibration that is based on several pressure standards. High-pressure x-ray powder diffraction measurements $(<6 \mathrm{GPa}$ ) were performed by the white-beam energy-dispersive method using synchrotron radiation and a multianvil press, MAX80, at HASYLAB in Hamburg, Germany. The sample was mixed with a fine $\mathrm{NaCl}$ powder which was used both as a pressure calibrator and a pressure medium. The pressure was estimated from the lattice constant of $\mathrm{NaCl}$ using the Decker equation of state at room temperature. ${ }^{13}$

Figure 2 shows high-pressure in situ electrical resistivity for bulk and nanocrystal $\mathrm{PbS}$. For bulk $\mathrm{PbS}$, the resistivity at low pressures is found to be a few $\mathrm{k} \Omega \mathrm{cm}$ and remains almost unchanged by $2.3 \mathrm{GPa}$. At $2.4-3.8 \mathrm{GPa}$ there is a sharp rise in resistivity by three orders of magnitude. The mean transition pressure is about $3.1 \pm 0.7 \mathrm{GPa}$. The transition is essentially complete by $4 \mathrm{GPa}$, at which point the resistivity starts to decrease again, which will be discussed later. For nanocrystal $\mathrm{PbS}$, the resistivity at low pressures is slight higher than that for bulk $\mathrm{PbS}$, which could be explained by

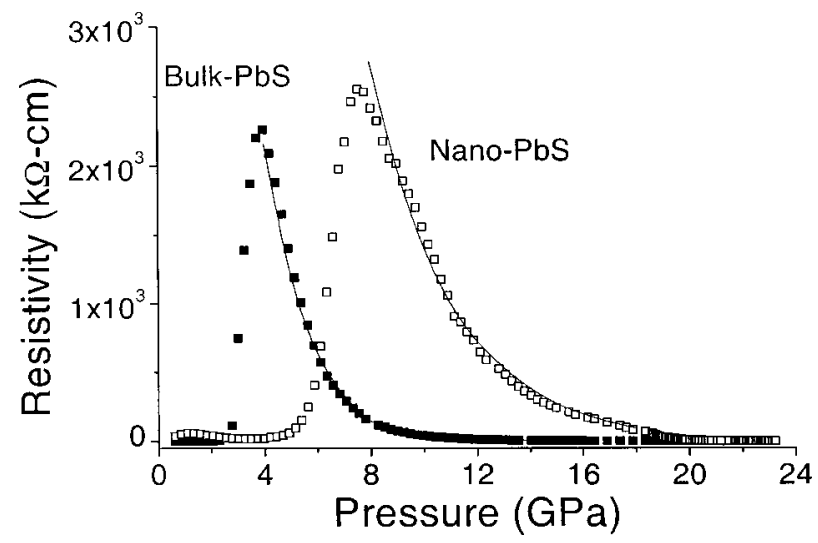

FIG. 2. High-pressure in situ electrical resistance for $\mathrm{PbS}$ materials with average grain sizes of $10 \mu \mathrm{m}$ and $8 \pm 1 \mathrm{~nm}$ at ambient temperature.
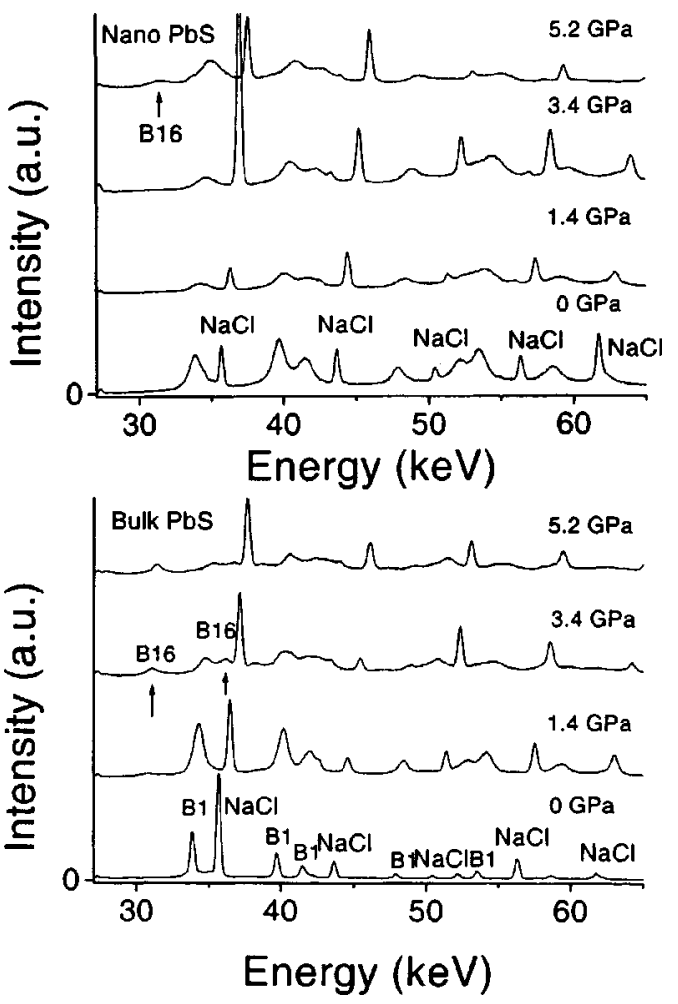

FIG. 3. Examples of in situ high-pressure synchrotron radiation x-ray powder diffraction patterns at room temperature with increasing pressures for 10 $\mu \mathrm{m}$ and $8 \pm 1 \mathrm{~nm} \mathrm{PbS} \mathrm{B1}$ and B16 are the low- and high-pressure phases, respectively.

an enhancement of the energy band gap of the B1 phase with decreasing grain size. ${ }^{14}$ No appreciable change of the resistivity was detected up to $5 \mathrm{GPa}$ and a sharp rise in resistivity was observed from 5 to $7.6 \mathrm{GPa}$. The mean transition pressure is about $6.3 \pm 1.3 \mathrm{GPa}$. Figure 3 shows high-pressure $\mathrm{x}$-ray powder diffraction patterns for both bulk and nanocrystal $\mathrm{PbS}$. The quality of data recorded here is similar to that reported by Qadri et al. ${ }^{12}$ Although the patterns of $\mathrm{NaCl}$ and $\mathrm{PbS}$ are superimposed, it is clear that in bulk $\mathrm{PbS}$, the high-pressure B16 phase can be detected at $3.4 \mathrm{GPa}$ while it is not observable at this pressure within experimental uncertainty for nanocrystal PbS. At 5.2 GPa, one peak of the B16 phase is visible also for nanocrystal $\mathrm{PbS}$. These results are consistent with the resistivity data above and confirm the sharp rise in resistivity originating from the B1-to-B16 phase transformation. Table I lists the onset, completion, and mean transition pressures of the B1-to-B16 phase transformation in $\mathrm{PbS}$. It can be seen that the onset pressure reported by Qadri et al. ${ }^{12}$ for $8.8 \mathrm{~nm} \mathrm{PbS}$ crystals is lower than that obtained in

TABLE I. Transition pressures of the B1-to-B16 phase transformation in $\mathrm{PbS}$.

\begin{tabular}{lllcl}
\hline \hline $\begin{array}{c}\text { Grain size } \\
(\mathrm{nm})\end{array}$ & $\begin{array}{c}\text { Onset } \\
(\mathrm{GPa})\end{array}$ & $\begin{array}{c}\text { Completion } \\
(\mathrm{GPa})\end{array}$ & $\begin{array}{c}\text { Mean } \\
(\mathrm{GPa})\end{array}$ & \multicolumn{1}{c}{ Reference } \\
\hline $10^{4}$ & $2.4 \pm 0.2$ & $3.8 \pm 0.2$ & $3.1 \pm 0.7$ & $\begin{array}{l}\text { Present work } \\
8.8\end{array}$ \\
2.4 & 5.8 & & Qadri et al. (Ref. 12) \\
$8 \pm 1$ & $5.0 \pm 0.2$ & $7.6 \pm 0.2$ & $6.3 \pm 1.3$ & $\begin{array}{l}\text { Present work } \\
5.4\end{array}$ \\
3.0 & 8.0 & & Qadri et al. (Ref. 12) \\
2.6 & 3.3 & 9.0 & & Qadri et al. (Ref. 12) \\
\hline \hline
\end{tabular}


this work for $8 \pm 1 \mathrm{~nm}$ Pbs nanocrystals. This discrepancy could be due to (1) different sample preparation methods used and (2) different techniques used to estimate transition pressures. On the basis of the combined in situ high-pressure conductivity and x-ray powder diffraction measurements, it can be concluded that the mean transition pressure of the B1-to-B16 phase transformation in nanocrystal $\mathrm{PbS}$ is higher than that in bulk PbS.

As seen in Fig. 2, the resistivity of the high-pressure phase (B16) in both bulk and nanocrystal PbS drops rapidly with increasing pressure. For bulk $\mathrm{PbS}$, it decreases by about three orders of magnitude between 4 and $10 \mathrm{GPa}$, and above $10 \mathrm{GPa}$, the resistivity levels off rapidly, decreasing only by about a factor of 10 over the range of 10-23 GPa. Similar behavior of the resistivity of the B16 phase versus pressure was also detected in nanocrystal $\mathrm{PbS}$. The data obtained from a pressure range of 4-14 GPa for bulk $\mathrm{PbS}$ and of 8-18 $\mathrm{GPa}$ for nanocrystal $\mathrm{PbS}$ were fitted by $d(\ln R) / d P=C$, where $C$ is constant. It found $C=-0.64 \mathrm{GPa}^{-1}$ for bulk $\mathrm{PbS}$ and $C=-0.34 \mathrm{GPa}^{-1}$ for nanocrystal $\mathrm{PbS}$, as is shown by the solid lines in Fig. 2. In general, resistivity of a semiconductor and a semimetal is determined by the energy band gap at a given temperature, as $R \propto \exp \left(-\Delta E_{g}\right) .{ }^{15}$ These results indicate a negative pressure coefficient for the energy gap of the B16 phase of $\mathrm{PbS}$. The magnitude of the slope, $d\left(\Delta E_{g}\right) / d P$, in nanocrystal $\mathrm{PbS}$ is found to be smaller than that in bulk $\mathrm{PbS}$. In fact, the high-pressure $\mathrm{B} 16 \mathrm{PbS}$ phase is isostructural with the black phosphorus B16 phase, in which both experimental and theoretical data ${ }^{16}$ did show $d\left(\Delta E_{g}\right) / d P<0$.

In summary, phase transition (B1-to-B16) in $\mathrm{PbS}$ with average grain sizes of $10 \mu \mathrm{m}$ and $8 \pm 1 \mathrm{~nm}$ has been investigated by in situ high-pressure electrical resistance and synchrotron radiation $\mathrm{x}$-ray powder diffraction measurements. The mean transition pressure of the B1-to-B16 phase transformation was found to be $6.3 \pm 1.3 \mathrm{GPa}$ for $8 \pm 1 \mathrm{~nm} \mathrm{PbS}$ while it is $3.1 \pm 0.7 \mathrm{GPa}$ for $10 \mu \mathrm{m} \mathrm{PbS}$. Thus, the smaller the crystallite, the higher the transition pressure. A similar grain-size effect on transition pressure has also been found in $\mathrm{CdSe}, \mathrm{ZnO}$, and $\mathrm{ZnS}$. The resistivity of the $\mathrm{B} 16 \mathrm{PbS}$ phase decreases exponentially with pressure in both samples. They follow the empirical law $R \propto \exp (-C P)$, where $C$ $=-0.64 \mathrm{GPa}^{-1}$ for $10 \mu \mathrm{m} \mathrm{PbS}$ and $C=-0.34 \mathrm{GPa}^{-1}$ for $8 \pm 1 \mathrm{~nm} \mathrm{PbS}$. This behavior can be explained by the decrease of the energy band gap of the $\mathrm{B} 16 \mathrm{PbS}$ phase with increasing pressure.

The authors thank HASYLAB-DESY Laboratory for the use of the synchrotron radiation facilities. Financial support from the Danish Technical Research Council, the Danish Natural Science Research Council, and the Large Scale Facility program at the Bayerisches Geoinstitut is gratefully acknowledged.

${ }^{1}$ See, for example, Nanophase Materials: Synthesis-PropertiesApplications, edited by G. C. Hadjipanayis and R. W. Siegel (Kluwer Academic, Dordrecht, 1994); Fundamental Properties of Nanostructured Materials, edited by D. Fiorani and G. Sberveglieri (World Scientific, Singapore, 1994).

${ }^{2}$ M. Bruchez, Jr., M. Moronne, P. Gin, S. Weiss, and A. P. Alivisatos, Science 281, 2013 (1998).

${ }^{3}$ W. C. W. Chan and S. Nie, Science 281, 2016 (1998).

${ }^{4}$ S. H. Tolbert and A. P. Alivisatos, Science 265, 373 (1994).

${ }^{5}$ S. H. Tolbert and A. P. Alivisatos, J. Chem. Phys. 102, 4642 (1995).

${ }^{6}$ S. H. Tolbert, A. B. Herhold, L. E. Brus, and A. P. Alivisatos, Phys. Rev. Lett. 76, 4385 (1996).

${ }^{7}$ J. Z. Jiang, L. Gerward, D. Frost, R. Secco, J. Peyronneau, and J. Staun Olsen, J. Appl. Phys. 86, 6608 (1999).

${ }^{8}$ J. Z. Jiang, J. Staun Olsen, L. Gerward, D. Frost, D. Rubie, and J. Peyronneau, Europhys. Lett. (in press).

${ }^{9}$ J. Z. Jiang, J. Staun Olsen, L. Gerward, and S. Møup, Europhys. Lett. 44, 620 (1998).

${ }^{10}$ J. Staun Olsen, L. Gerward, and J. Z. Jiang, J. Phys. Chem. Solids 60, 229 (1999).

${ }^{11}$ T. Chattopadhyay, H. G. von Schnering, W. A. Grosshans, and W. B. Holzapfel, Physica B 139\&140, 356 (1986).

${ }^{12}$ S. B. Qadri, J. Yang, B. R. Ratna, E. F. Skelton, and J. Z. Hu, Appl. Phys. Lett. 69, 2205 (1996).

${ }^{13}$ D. L. Decker, J. Appl. Phys. 42, 3239 (1971).

${ }^{14}$ Y. Wang, A. Suna, W. Mahler, and R. Kasowski, J. Chem. Phys. 87, 7315 (1987); O. D. Sanctis, K. Kadono, H. Tanaka, and T. Sakaguchi, Mater. Res. Soc. Symp. Proc. 358, 258 (1995)

${ }^{15}$ J. Bardeen and W. Shockley, Phys. Rev. 80, 72 (1950).

${ }^{16}$ S. Sugai, T. Ueda, and K. Murase, J. Phys. Soc. Jpn. 50, 3356 (1981); H. Asahina, K. Shindo, and A. Morita, ibid. 51, 1193 (1982); Y. Akahama, S. Endo, and S. Narita, Physica B 139\&140, 397 (1986). 